\title{
Comparison assessment between SIM and MRM mode in the analysis of 3-MCPD ester, 2-MCPD ester and glycidyl ester
}

\begin{abstract}
The detection of 3- and 2-MCPD ester and glycidyl ester was transformed from selected ion monitoring (SIM) mode to multiple reaction monitoring (MRM) mode by gas chromatography triple quadrupole spectrometry. The derivatization process was adapted from AOCS method Cd 29a-13. The results showed that the coefficient of determination (R2) of all detected compounds obtained from both detection mode was comparable, which falls between 0.997 and 0.999 . The limit of detection and quantification (LOD and LOQ) were improved in MRM mode as compared to SIM mode. In MRM mode, the LOD of 3- and 2MCPD ester was achieved $0.01 \mathrm{mg} / \mathrm{kg}$ while the LOQ was $0.05 \mathrm{mg} / \mathrm{kg}$. Besides, LOD and LOQ of glycidyl ester were 0.024 and $0.06 \mathrm{mg} / \mathrm{kg}$ respectively. A blank spiked with MCPD esters $(0.03,0.10$ and $0.50 \mathrm{mg} / \mathrm{kg})$ and GE $(0.06,0.24$ and $1.20 \mathrm{mg} / \mathrm{kg})$ were chosen for repeatability and recovery tests. MRM mode showed better repeatability in area ratio and recovery with relative standard deviation (RSD \%) $<5 \%$ for $2-, 3-\mathrm{MCPD}$ ester at $0.5 \mathrm{mg} / \mathrm{kg}$ and GE at $1.2 \mathrm{mg} / \mathrm{kg}$. Quantification of 22 food samples from different category were performed by repeated injections in both detection modes. Briefly, the contaminants from crude palm oil, mustard and olive oil were present in minute amount which below the LOD or LOQ in both detection modes. Sample from chocolate and infant formula products showed certain level of MCPD esters and GE, and their detection was more precisely quantitated based on MRM mode. Besides, margarine products showed a higher level of contaminations due to the high fat content in these products. MRM mode detection was proven to provide precise data with low RSD \% in different food matrices. MRM mode detection was robust and selective for MCPD esters and GE analyses, it should be applied to determine the concentration of MCPD esters and GE contaminations in food.
\end{abstract}

Keyword: Food safety; GC MS/MS; Glycidyl ester; MCPD ester; Multiple reactions monitoring; Limit of detection; Limit of quantification 